\title{
EDITORIAL
}

\section{Research collaboration}

The term 'collaboration' is defined as 'working together to achieve a common goal'. Working together could be by two or more persons or organizations. When working together, the individuals or the organizations will share their knowledge, experience and resources and work as a team to achieve the set goals.

It is widely recognized that research collaboration 'is a good thing' and should be encouraged especially when it is between universities/institutions and the industry. Most researchers recognize the importance of collaboration and working in partnership with colleagues both within and outside their countries. One fifth of world's scientific papers are co-authored internationally (AUCC, 2009). Thus, many countries have developed policies in order to encourage research collaboration, especially international collaboration, where it is expected to bring about costsaving and other benefits to institutions.

Research collaboration can occur at different levels. They can either be between (inter) or within (intra) different levels. Thus, inter-national collaboration means collaboration between nations while intra-national collaboration means collaboration within a single nation. However, there may be occasions when a collaboration cannot be clearly classified since it may appear to belong to both an intra and an inter category. For example, collaboration that involving two or more domestic institutions and a foreign institution is clearly an interinstitutional collaboration. But from one perspective this collaboration also constitutes an inter-national collaboration (domestic and foreign), while from another perspective it can be considered a mixture of inter and intra national collaboration. Thus, we see that a collaboration can be either homogeneous (either inter or intra without ambiguity) or heterogeneous [a mixture of inter and intra forms of collaboration (Katz \& Martin, 1997)].

What motivates or encourages research collaboration? One of the major factors contributing to research collaboration is the escalating research costs. When there is collaboration there will be a reduction in expenses, especially in fundamental research. Resources can be pooled, specialized knowledge and skills shared and costs of maintaining expensive equipment can be substantially reduced. International collaboration will also provide an avenue for the researcher to move into a wider network of contacts and participate in cutting-edge and innovative activity, to keep science successful and competitive and to become 'Global' and engage in 'Big Science'.

Many international organizations such as Food and Agriculture Organization (FAO), International Atomic Energy Agency (IAEA) of the United Nations, International Development Research Centre (IDRC), National Research Council (NRC), Chinese Academy of Sciences (CAS), Canadian International Development Agency (CIDA) and National Science Foundation (NSF) USA, to name a few, promote research collaboration mainly because it helps to incorporate complementary perspectives and resources to solving a common problem. On one hand, such collaborations lead to sharing of knowledge, expertise and partnerships. On the other hand, primarily dedicated to young scientists, organizations such as International Foundation for Science (IFS) promotes global partnerships amongst young scientists, helping to improve the visibility by association with 'elites' in the field. The International Council for Science (ICSU), with a mission to strengthening international science for the benefit of society promotes interdisciplinary partnerships addressing key issues of relevance to both science and society (i.e. sustainable development, Earth Summit, Rio +20 etc.).

Apart from intellectual, economic and social benefits, international research collaboration leading to multiple authorships is known to increase the citation performance of papers. Citations per article have increased with the increase in number of collaborating countries (Muller, 2008), reflecting upon the impact of the publications.

Research collaboration, especially when interdisciplinary in nature, can bring about significant 
scientific advances. Where individual knowledge and skills are limited, bringing together of scientists from various disciplines can lead to scientific 'break throughs', as seen in major technologies such as bio and nano technologies. International research partnerships have played a major role in increasing food production and availability in many developing countries. Green Revolution is one successful example of such a partnership, which had a significant impact upon the economic development of Mexico and India. International partnerships have also helped to build capacity to better confront infectious diseases such as HIV/AIDS and AIDS associated diseases in the African continent, develop sustainable production systems in agriculture, promote technology transfer and in general, enhance the research capabilities of National Research Systems in developing countries (Paul et al., 2008).

How is research collaboration measured? Based on the belief that collaboration usually brings about a published paper, multiple authorship can be used to measure research collaboration. However, the nature and magnitude of the contribution of the individuals may not be measurable through this, since there have been many instances where colleagues were given 'honorary co-authorship' or in other cases, authorships for social reasons. Based on Thomson ISI publications data, there has been a considerable increase in the volume of international collaborative research activity leading to co-authorships in most developed countries from 1995 to 2005. The increase in research output as measured by published articles has been around $50 \%$ for Australia, $45 \%$ for UK and Japan and over $110 \%$ for China. The USA, Canada, France and Germany were around 40\% (Adams et al., 2007).

What are the barriers to research collaboration? Whether it be inter or intra collaboration there could be many barriers to research collaboration. Amongst the most crucial could be language and cultural differences (international collaboration with developing country partners), cost, politics, slow communication and even finding the right collaborator at the right time. Practical issues such as mutual trust amongst the collaborators, direction and distribution of work, selection of a leader, data sharing, distribution of credit and rewards and rights of intellectual property are further factors that may influence collaboration.
What is the scenario in Sri Lanka? Considering the period $2000-2008,50 \%$ of research grants awarded by the National Science Foundation (NSF) and $40 \%$ of research grants awarded by the Council for Agriculture Research Policy (CARP), the two major research funding organizations in the country, have been for collaborative research. Collaboration has been between scientists from different departments of the same institute $(30-40 \%)$ as well as between institutes (20\%). International collaboration however, has been negligible. With regard to publications during the same period, $80 \%$ of the articles published in the Journal of the National Science Foundation, the only Sri Lankan journal cited in the Thomson ISI, have been co-authored but international co-authorship has once again been negligible.

International collaborations are increasingly necessary to deal with global challenges. However, the stake holders must ensure that they create the conducive atmosphere where international collaboration can truly thrive and bear fruit. Virtualization that draw scientists together outside geographical boundaries is becoming a major tool of the future international collaboration. Thus, e-science has a major role to play in the future of international collaborations.

\section{REFERENCES}

1. Adams J., Gurney K. \& Marshall S. (2007). Patterns of International Collaboration for the UK and Leading Partners (Summary Report). A report commissioned by the UK Office of Science and Innovation, June 2007. http:// www.bis.gov.uk/files/file40396.pdf.

2. Association of Universities and Collages of Canada (AUCC) (2008). AUCC Internationalization Survey Update, 2008. Association of Universities and Colleges of Canada, Ontario, Canada.

3. KatzJ.S. \& Ben R.M. (1997). What is research collaboration? Research Policy 26: 1-18.

4. Muller M. (2008). International research collaboration: just nice to have or necessary. Global Research Collaborations, Merrill Series on the Research Mission of Public Universities (ed. Mabel L. Rice), MASC Report No. 112. The University of Kansas, Kansas, USA.

5. Paul P.S., Wood C. \& Yohe J. (2008). Lessons learned from international research partnerships. Global Research Collaborations, Merrill Series on The Research Mission of Public Universities (ed. Mabel L. Rice), MASC Report No. 112. The University of Kansas, Kansas, USA.

M.C.N. Jayasuriya 